\title{
Optical and Photoacoustic Properties of Colloidal Silver Nanoparticles Solutions
}

\author{
F. M. Aldosari' ${ }^{1}$, A. M. Azzeer², \& A. M. Hassib² \\ ${ }^{1}$ Physics Department, Applied and Natural Sciences, Prince Sattam Bin Abdulaziz University, Saudi Arabia \\ ${ }^{2}$ Physics and Astronomy Department, College of Science, King Saud University, Saudi Arabia \\ Correspondence: F. M. Aldosari, Physics Department, Applied and Natural Sciences, Prince Sattam Bin Abdulaziz \\ University, Saudi Arabia. Tel: 966-116-826-600. E-mail: fah.aldosari@psau.edu.sa
}

Received: May 17, 2018

Accepted: June 14, 2018

Online Published: July 20, 2018

doi: $10.5539 /$ jmsr.v7n4p1

URL: https://doi.org/10.5539/jmsr.v7n4p1

\begin{abstract}
The study has aimed to investigate optical and photoacoustic properties of some colloidal silver nanoparticles at different concentration over the time. The phase purity with crystal structure of silver nanoparticles were studied using X-ray diffraction (XRD) and was confirmed by Transmission Electron Microscopy (TEM). Optical property was changed during the variable concentration of nanoparticles and duration time of sample. The absorbance of silver colloidal solutions is increased, when concentration increases but decreased with respective to the longer period of sample. Absorption peaks and stability of particles in solutions is influenced by the duration time of solution and its concentration. The low concentration-based solutions fall in the absorbance over the times. The observed PA signal is subjected by the factor of parameters; such as, pump wavelengths, energy, repetition rate, concentrations, and temperature. Stability of fluorescence and absorption peaks are influenced by the concentration of particles and time period of colloidal solution. Effects on PA signal with fluorescent and absorption peaks upon the concentration was also significant.
\end{abstract}

Keywords: silver nanoparticles, absorption, photoluminescence, photoacoustic

\section{Introduction}

Fabrication and characterization of metals based nanostructured materials have been thoroughly discussed because of their novel material properties; such as, optical, electronic, magnetic, and catalytic properties (Ozin, 1992) that are dependent on their structure with size and shape (May, 2008; Cao, 2004). Silver based nano-crystallites are one of the metal nanoparticles that have widely been discussed because of their potential materials for various applications in catalysis (Shiraishi \& Toshima, 2000; Sun \& Seff, 1994), electrical conductivity (Chang \& Yen, 1995), and optical properties (Popok, Stepanov, \& Odzhaev, 2005). In this context, researchers have reported on the optical properties of silver nanoparticles (NPs) in accordance with the surface plasma, where the electromagnetic field induced collective oscillation of conduction band electrons (Kreibig \& Vollmer, 2013; Bohren \& Huffman, 1983). A strong absorption in UV-Vis spectral region due to plasmon modes is observed; and the shape and position of plasmonic absorption bands of metal NPs were related to particles size, dielectric constant, composition, and dielectric constant of the surrounding media (Jin et al., 2001; Link \& El-Sayed, 1999). Moreover, a small changing at the size and shape of metal NPs exhibits different color that can cover wide spectral range. Such significant effects can lead to many potential applications in various fields; such as, microelectronics and optics (Förster \& Antonietti, 1998; Alivisatos, 1996). Though the above studies have reported on optical and electrical properties, detailed spectroscopic studies are required to characterize various properties including optical properties (Villegas et al., 1996; Wang et al., 1997; Borsella et al., 1998; Ferrari et al., 1999).

The photoacoustic technique is considered as another advantage of principal of sound generation, which is based on light absorption, introduced by Bell (1881). This technique is rarely used for investigating the sound generation especially for metal nanoparticles, but recently using imaging works by shining pulsed light onto tissue labeled with optical absorbers; i.e., nanoparticles, dyes, etc. were reported (Emelianov et al., 2004; Emelianov et al., 2004. This was able to record with the anatomical images provided by ultrasound due to the existence of nano size particles inside tissue. The photoacaustic imaging technique was employed for using biomedical science (Oraevsky, Jacques \& Tittel, 1997; Kruger, 1994; Ku et al., 2005; Wang et al., 2002). Properties of silver nanoparticles can also be used in the wide range of different field of integrated circuits, biosensors, medical imaging, drug delivery, hyperthermia therapy, chemosensors, electrochemical sensors, bio labeling, and filters because of exhibiting an 
antibacterial activity as well as surface plasmon resonance (Pal, Tak, \& Song, 2007; Abbasi et al., 2016; Amendola \& Meneghetti, 2009; Fukasawa et al., 2014; Schröfel et al., 2014). In addition, many pure metals-based nanoparticles emerge unusual properties that have discussed optical, electrical, and magnetic properties (Chen et al., 2009; Garitaonandia et al., 2008; Hao \& Schatz, 2004; Mock et al., 2002; Sun, \& Xia, 2002). Till date, limited studies on the evolution of photoacaustic signal of silver nanoparticles are reported. Recently, photoacaustic response from Ag-Au alloy NPs in water using short pulse was reported (Hatef et al., 2015). In this study, basic characteristics of different concentration based colloidal silver nanoparticles over the different times by optical and photoacaustic technique have been discussed.

\section{Experimental Details}

The colloidal silver nanoparticles solutions were prepared using triple distilled water in an ultrapure water purification system (Milli-Q Advantage A10, Millipore, USA). The silver nitrate (AgNO3, 99\%, LA Container Inc., USA) and sodium borohydride (NaBH4, 97\%, Fluka, Switzerland) were used in the preparation. The materials were mixed using ultrasonic for about 5 minutes to make homogeneous distribution of the particles. The mixed solution was refrigerated within an ice pan for about 10 minutes. After that, the mixture solution was homogenized under a hot plate with magnetic stirrer. A $10 \mathrm{~mL}$ volume of $1.0 \mathrm{mM}$ silver nitrate was added drop wise (about 1 drop/second) to $30 \mathrm{~mL}$ of $2.0 \mathrm{mM}$ sodium borohydride solution that had been chilled in an ice pan. The reaction mixture was stirred further vigorously on a magnetic stir plate. The solution turned light yellow after the addition of $2 \mathrm{~mL}$ of silver nitrate and it turned a brighter yellow when the silver nitrate had been added.

From the above experiment, the solution was prepared at the concentration of $\mathrm{C}_{0}=2.5 \times 10^{-3} \mathrm{M}$. Then different concentrations of the solutions were prepared at $\left(\mathrm{C}_{1}=1.25 \times 10^{-3} \mathrm{M}, \mathrm{C}_{2}=6.25 \times 10-4 \mathrm{M}, \mathrm{C}_{3}=3.125 \times 10^{-4} \mathrm{M}\right.$, $\left.\mathrm{C}_{4}=1.56 \times 10^{-4} \mathrm{M}, \mathrm{C}_{5}=7.8 \times 10^{-5} \mathrm{M}, \mathrm{C}_{6}=3.9 \times 10^{-5} \mathrm{M}, \mathrm{C}_{7}=1.95 \times 10^{-5} \mathrm{M}, \mathrm{C}_{8}=9.76 \times 10^{-6} \mathrm{M}\right)$ by diluting $\mathrm{C}_{0}$ with water. The UV-Visible spectrophotometer (Lambda 40, Perkin Elmer, USA) was used to obtain the absorption spectra of silver nanoparticles in the spectral range from $190 \mathrm{~nm}$ to $1100 \mathrm{~nm}$. Luminescence Spectrometer (LS45, Perkin Elmer, USA) was used to obtain the emission, excitation spectra, and synchronous fluorescence. The particles size and crystallite structure were studied by a transmission electron microscopy (JEM-2100F field emission electron microscope, JEOL, Japan), The X-ray Diffraction (X'Pert Pro, wavelength 1.54056 §, PANalytical, Netherlands) was used for phase analysis to understand the crystal structure of the silver nanoparticles using High Score.

\section{Photoacoustic Setup}

The photoacoustic configuration involves Nd: YAG laser (model LQ 129, Solar Laser System) with the-Pump energy $23 \mathrm{~J}$, Delay of output pulse relative to pump-pulse $154 \mu \mathrm{s}$, Output energy at $532 \mathrm{~nm}: 280 \mathrm{~mJ}$, Pulse energy at $532 \mathrm{~nm}: 280 \mathrm{~mJ}$, pulse repetition rate 1-10 Hz, Pulse width at $532 \mathrm{~nm}: 12 \mathrm{~ns}$, Beam divergence: $1 \mathrm{mrad}$, Polarization at $532 \mathrm{~nm}$ : horizontal, Rod diameter: $8 \mathrm{~mm}$. The third harmonic generator (model LG 103, Solar Laser System) with wavelength $(1064-532,355-\mathrm{nm})$ was used with the laser. In order to study the relationship between photoacoustic signal and wavelength, a titanium doped sapphire (Ti: Sapphire) laser (model LX 325, Solar Laser System) was used with the parameters of output energy $\sim 70 \mathrm{~mJ}$ at $755 \mathrm{~nm}, \sim 40 \mathrm{~mJ}$ at $885 \mathrm{~nm}$, Beam divergence at $755 \mathrm{~nm} \sim 1.5 \mathrm{mrad}$, Tuning range: $694-935 \mathrm{~nm}, 866-1012 \mathrm{~nm}$, Line-width at maximum of tuning curve $<0.8$ $\mathrm{nm}$.

The spectra of UV-Vis absorption with respect to the silver nanoparticles was acquired by using a UV-Visible Spectrophotometer (Lambda 40, Perkin Elmer, USA). In this way, the spectra with a wavelength ranging between $190 \mathrm{~nm}$ and $1100 \mathrm{~nm}$ was obtained. An all-reflecting optical system is present within this spectrophotometer, with silica-coated optical components. The monochromator uses a holographic grating; this is concave and has 1053 lines $/ \mathrm{mm}$ in the center. The range of working wavelengths with respect to the spectrophotometer is encapsulated through using deuterium and halogen lamps, that act as radiation sources. In order to operate in the visible (VIS) region, a mirror (M1) is used for reflecting radiation from the halogen lamp towards a second mirror (M2). Simultaneously, the deuterium lamp's radiation is blocked by M1. When ultra-violet (UV) operation is required, the radiation from the deuterium lamp is allowed to strike M2, by raising M1. The radiation passes through an optical filter towards the monochromator's entrance slit, following which a spectrum is produced, through dispersing it at the grating. A portion of this spectrum is selected on the basis of the grating's rotational orientation and reflected to a third mirror (M3) via an exit slit. From here, the radiation is reflected onto a beam splitter; this enables $50 \%$ of the radiation to pass onto a fourth mirror (M4) and the rest of the radiation is reflected onto a fifth mirror (M5). The radiation beam is focused into the sample cell by M4 and passes onto a photodiode detector via a convex lens. Whereas, M5 enables the radiation to be focused into a reference cell, thereby allowing it to pass onto the photodiode detector as well, via a convex lens. The spectra of excitation, emission, and synchronous fluorescence was acquired through the use of a Luminescence Spectrometer (LS45, Perkin Elmer, USA). 


\section{Results and Discussion}

\subsection{Absorption Spectra}

The concentration of silver nanoparticles in solution was taken as $\mathrm{C}_{0}=2.5 \times 10^{-3} \mathrm{M}$. In order to investigate the properties of silver nanoparticles as a function of different concentration, the first concentration of $\mathrm{C}_{0}$ was diluted in water to prepare different concentration as $\mathrm{C}_{1}, \mathrm{C}_{2}$ and further diluted in water to make $\mathrm{C}_{3}, \mathrm{C}_{4}$ and $\mathrm{C}_{5}$ and then diluted in water to make $\mathrm{C}_{5}$ and $\mathrm{C}_{7}$. The following concentration of colloidal silver nanoparticles was systematically studied on various parameters using different optical techniques

$$
\begin{array}{ll}
\mathrm{C}_{0}=2.5 \times 10^{-3} \mathrm{M} & \mathrm{C}_{1}=1.25 \times 10^{-3} \mathrm{M} \\
\mathrm{C}_{2}=6.25 \times 10^{-4} \mathrm{M} & \mathrm{C}_{3}=3.125 \times 10^{-4} \mathrm{M} \quad \mathrm{C}_{4}=1.56 \times 10^{-4} \mathrm{M} \\
\mathrm{C}_{5}=7.81 \times 10^{-5} \mathrm{M} & \mathrm{C}_{6}=3.9 \times 10^{-5} \mathrm{M} \mathrm{C}_{7}=1.95 \times 10^{-5} \mathrm{M}
\end{array}
$$

The absorption spectra of colloidal silver nanoparticles in solution at different concentration was recorded in the 200-700nm spectral region. The absorption peaks were noted to investigate the stability over time at different days. To understand the relative effects, concentration of silver nanoparticles in each solution were taken as half.

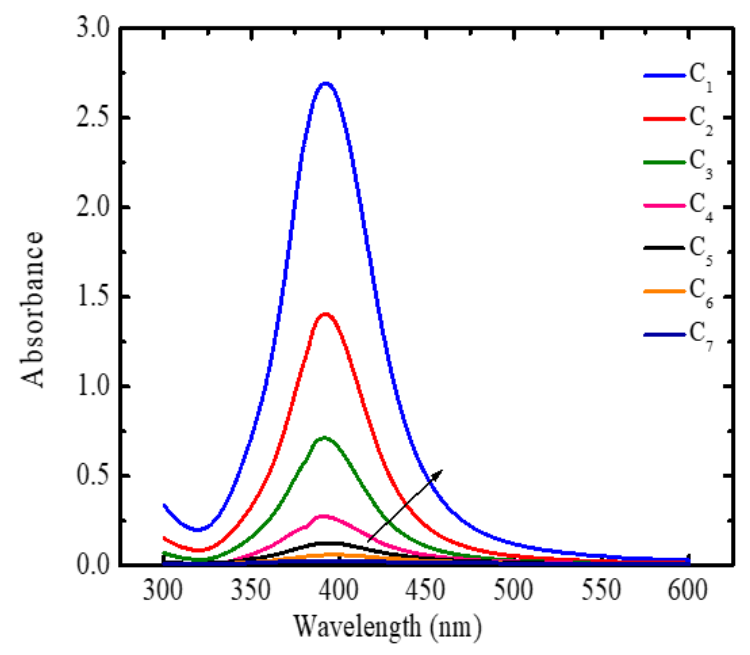

A

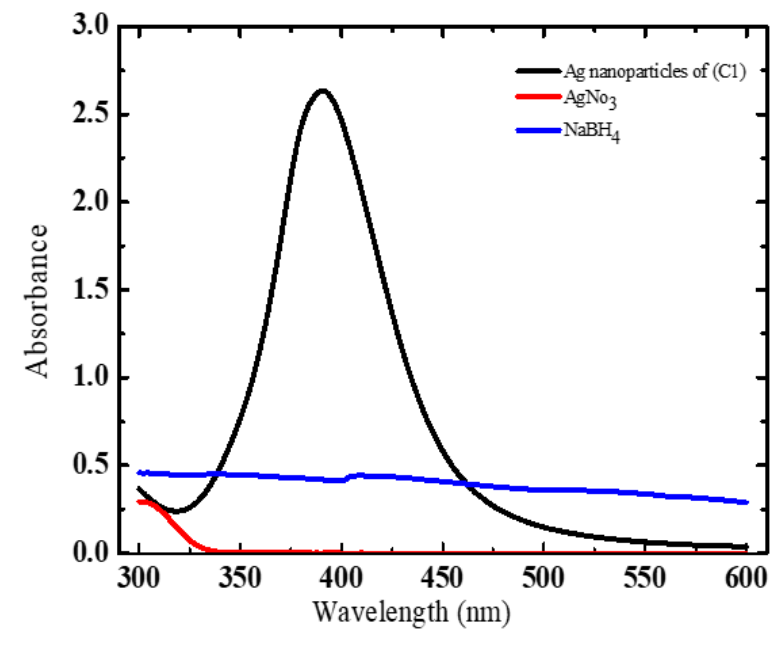

B

Figure 1. (a) UV-V is spectra of silver nanoparticles with different concentration; (b) Absorbance vs. Wavelength for $\mathrm{Ag}$ nanoparticles, $\mathrm{NaBH}_{4}$ and $\mathrm{AgNo}_{3}$

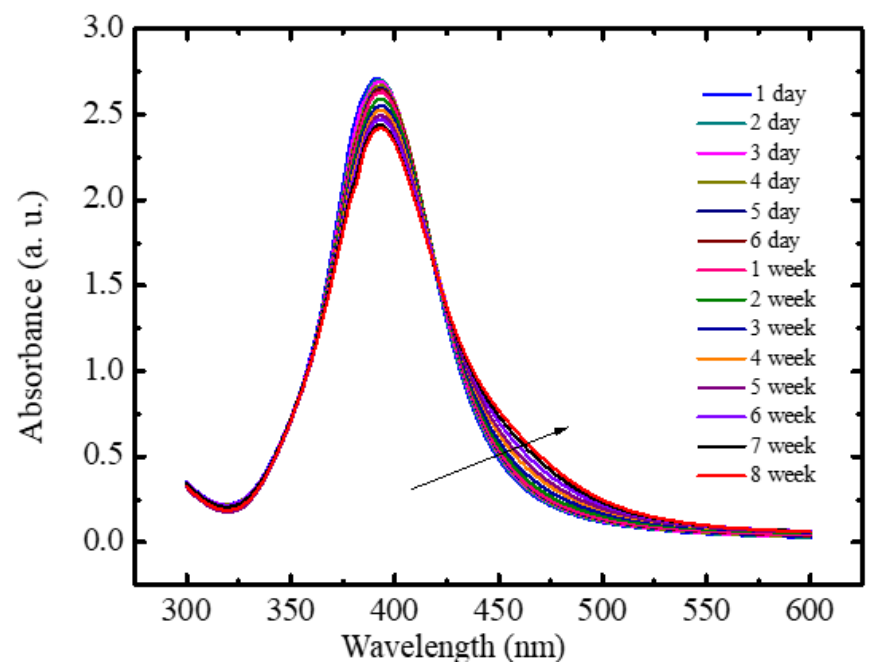

Figure 2. UV-V is spectra of silver nanoparticles of $\mathrm{C}_{1}$ over time 
The comparison absorption peaks of different silver nanoparticles solution are shown in Figure 1a and observed to be increment in their absorbance with respect to the level of concentration of nanoparticles. It is evident that the absorption, centered at $392 \mathrm{~nm}$ with strong high concentration of $\mathrm{C}_{1}$; but shift slightly toward longer waves as the concentration decreases. No significant changes were observed at absorption peak positions over time of samples. The absorption peak at 392 may attribute to the absorption characteristic around $400 \mathrm{~nm}$ of spherical Ag-NP (Oseguera-Galindo et al., 2012; Pyatenko, Yamaguchi, \& Suzuki, 2007).

The comparison of absorbance of silver nitrate $\left(\mathrm{AgNo}_{3}\right)$, sodium borohydride $\left(\mathrm{NaBH}_{4}\right)$, and silver nanoparticles $(\mathrm{Ag})$ was examined and confirmed the absorption peak of silver nanoparticles as shown in fig. 1b. The stability of silver nanoparticles with different concentration in solution over the time was examined by the absorbance of its first preparation and after the interval of days and weeks till several weeks. The absorption spectra of silver nanoparticles for different concentration over the different days namely from $C_{1}$ to $C_{7}$ are shown in Figures 2-4. As displayed in figure 2. The comparison of evolution on absorption spectra of silver nanoparticles for $\mathrm{C}_{1}$ over the different days.

A
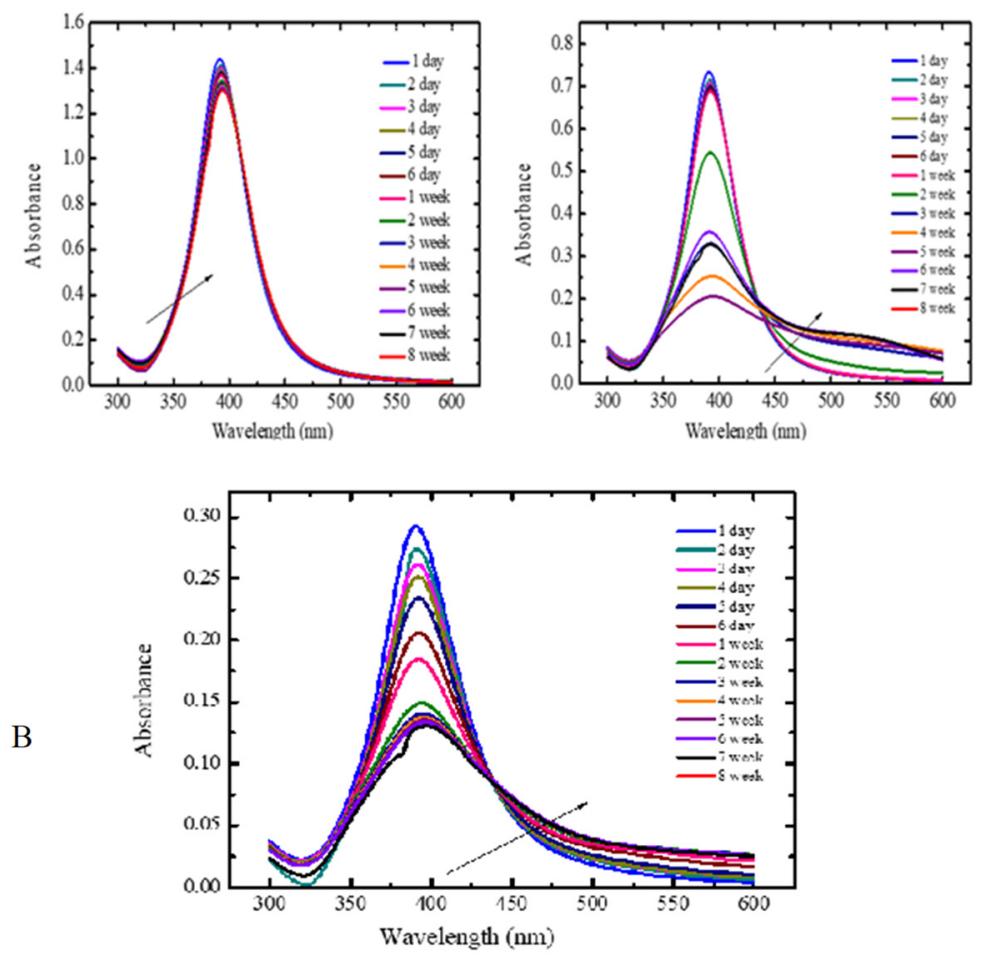

Figure 3. (a) UV-Vis spectra of silver nanoparticles of $\mathrm{C} 2$ over time; (b) UV-Vis spectra of silver nanoparticles of $\mathrm{C} 3$ over time

The absorbance shows the consistency and seems to be non-aggregation for the period of 8 weeks after preparation. However, there are certain slight effects on peaks position over the time. Similar behavior of absorption is observed at $\mathrm{C}_{2}$ which is different at concentration from $\mathrm{C}_{1}$, but when the concentration of the solution is reduced to half of $\mathrm{C}_{2}$; for instance, $\mathrm{C}_{3}$ and $\mathrm{C}_{4}$ (half of $\mathrm{C}_{3}$ ), the absorption property is significantly changed after 4 days as shown in Figure $3(\mathrm{a}, \mathrm{b}, \mathrm{c})$. The absorbance is decreased as the time period of sample increases.

The same characteristic of absorption observed, when the concentration is decreased as shown in figure $4(a, b, c)$. The absorbance of lower concentration of silver nanoparticles is more influenced by the days. As the concentration of $\mathrm{C}_{5}$ is half $\mathrm{C}_{6}$, the effect on absorbance over the time is significant as seen in figure $4 \mathrm{~b}$. Moreover, the absorbance of $\mathrm{C}_{7}$ (half of $\mathrm{C}_{6}$ ) is dramatically decreased just after one day and till few days. Interestingly, the absorption peaks of silver nanoparticles at all concentration are occurred slightly red-shift over the time. No major significant shift in position during the short period of time from 1-day till to 2 weeks is observed. Four weeks later, the position of absorption peak has a slightly red-shift from 397 to $402 \mathrm{~nm}$, suggesting the formation of larger particles without any aggregation. The details of absorption peaks for all concentration over the time are listed in table 1 . Even after 2 months, plasmonic absorbance remained at $404 \mathrm{~nm}$, and no aggregation is observed. Thus, it may possible that colloidal silver nanoparticles can remain stable at room temperature for several weeks. 
The absorbance stability of colloidal silver nanoparticles over times is plotted in figure 5a. Stability is observed at different concentration except slightly falls at $\mathrm{C}_{3}$. Majority of the colloidal samples at different concentration has decreased in absorbance as the time period increases; for instance, as compared between the solution of first day and after 8 weeks as displayed in figure $5 \mathrm{~b}$. Over all, the shifts in absorption peak of silver nanoparticles may depend on the particle size, surrounding chemical and dielectric constant etc. as reported by (Liz-Marzán, 2006).
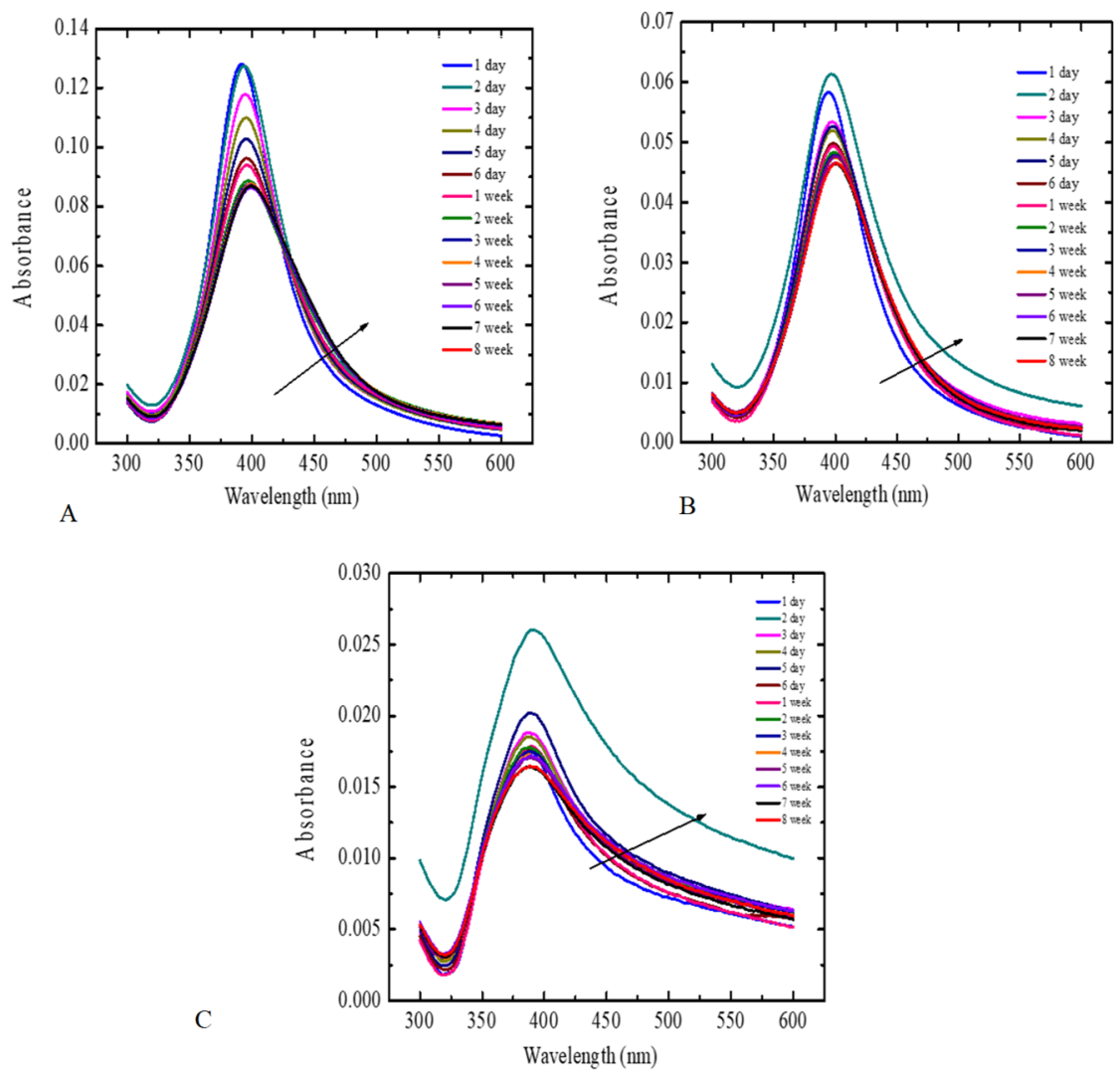

Figure 4. (a) UV-Vis spectra of silver nanoparticles of C5 overtime; (b) UV-Vis spectra of silver nanoparticles of C6 overtime; (c) UV-Vis spectra of silver nanoparticles of C7 overtime

Table 1. The absorption peak positions of silver nanoparticles for different concentrations with respect to time

\begin{tabular}{lllllllll}
\hline Time (min) & $\boldsymbol{\lambda}(\mathbf{n m})$ & $\boldsymbol{\lambda}(\mathbf{n m})$ & $\boldsymbol{\lambda}(\mathbf{n m})$ & $\boldsymbol{\lambda}(\mathbf{n m})$ & $\boldsymbol{\lambda}(\mathbf{n m})$ & $\boldsymbol{\lambda}(\mathbf{n m})$ & $\boldsymbol{\lambda}(\mathbf{n m})$ \\
\hline & $\mathrm{C}_{1}$ & $\mathrm{C}_{2}$ & $\mathrm{C}_{3}$ & $\mathrm{C}_{4}$ & $\mathrm{C}_{5}$ & $\mathrm{C}_{6}$ & $\mathrm{C}_{7}$ \\
(1 day) & 392 & 392 & 390 & 390 & 392 & 394 & 382 \\
(2D) & 392 & 392 & 392 & 392 & 394 & 397 & 398 \\
(3D) & 392 & 392 & 392 & 392 & 394 & 398 & 388 \\
(4D) & 392 & 392 & 392 & 392 & 396 & 398 & 388 \\
(5D) & 394 & 392 & 392 & 392 & 396 & 398 & 388 \\
(6D) & 394 & 394 & 392 & 392 & 396 & 398 & 388 \\
(1 week) & 394 & 392 & 392 & 392 & 396 & 398 & 388 \\
(2 week) & 394 & 394 & 392 & 394 & 398 & 400 & 388 \\
(3 week) & 394 & 394 & 392 & 396 & 398 & 400 & 388 \\
(4week) & 394 & 394 & 392 & 396 & 400 & 400 & 388 \\
(5 week) & 394 & 394 & 392 & 396 & 400 & 400 & 388 \\
(6 week) & 394 & 394 & 392 & 396 & 400 & 400 & 388 \\
(7 week) & 392 & 394 & 392 & 398 & 400 & 400 & 390 \\
(8 week) & 394 & 394 & 394 & 398 & 400 & 400 & 388 \\
\hline
\end{tabular}




\subsection{X-Ray Diffraction (XRD)}

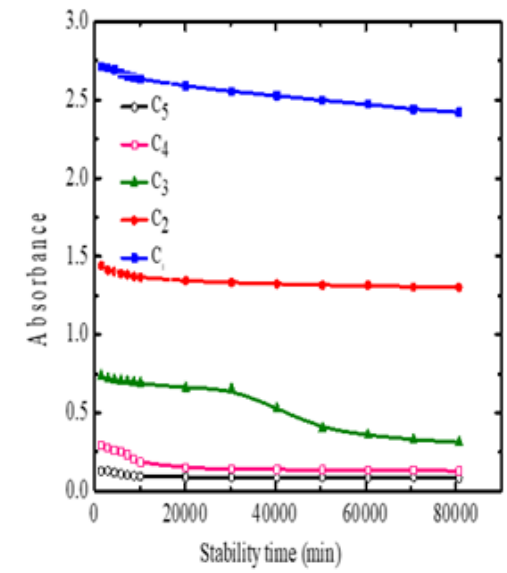

A

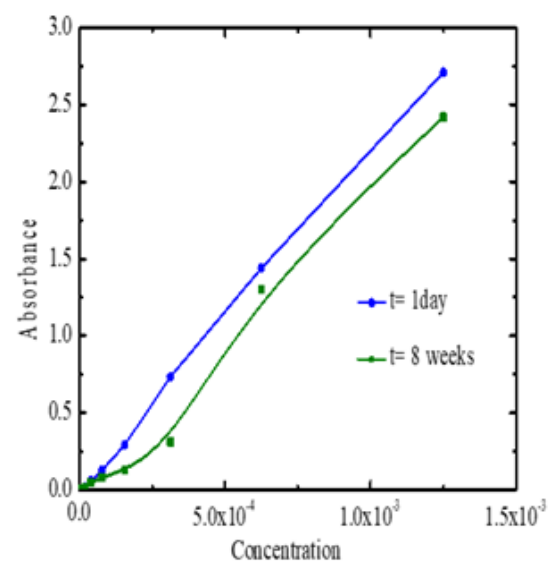

B

Figure 5. (a) Absorbance vs. Stability time from 1 day to 8 weeks; (b) Absorbance vs. Concentration of silver nanoparticles

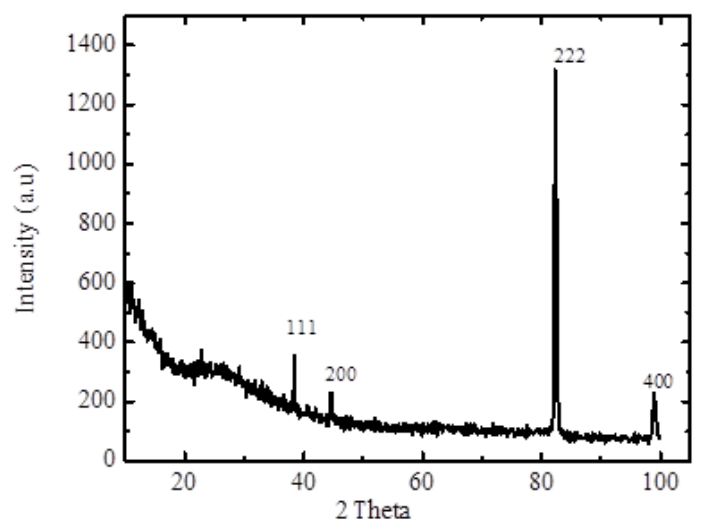

Figure 6. X-Ray Diffraction pattern of silver nanoparticles

The nature of silver nanoparticles was determined by XRD (X'Pert Pro, PANalytical, Netherlands). The structure is observed to be highly crystalline in nature. The typical XRD pattern of silver nanoparticles solution indicates a cubic crystal structure as shown in Figure 6. The peaks of silver particles appear at $2 \theta=38.48^{\circ}, 44.67^{\circ}, 82.4^{\circ}$ and $98.99^{\circ}$, which attributes to crystal faces of $111,200,222$ and 400 . The peaks observed at $2 \theta=38.48^{\circ}, 44.67^{\circ}$ correspond to [llll 111$],\left[\begin{array}{lll}2 & 0 & 0\end{array}\right]$, of crystal planes of a cubic lattice structure of silver nanoparticles as reported by Wang \& Chen (2008). All the reflection peaks could be indexed to face-centered cubic (FCC) of silver, suggested that nanoparticles were not changed in their crystalline structure. Particles sizes were determined using the complete width at the half-maximum of the diffraction peaks and found to be as 39, 51, 27, $21 \mathrm{~nm}$ ). The average size of the particles was estimated d by the following Scherrer equation (1) and obtained the value as $34.5 \mathrm{~nm}$. However, it is important to take into consideration that XRD does not give the exact structural dimensions pertaining to nanoparticles, since it averages over the atomic distances. Moreover, nanoparticles themselves possess a great level of structural disorder and displacement, instead of having a high number of X-ray scattering sources.

$$
D_{n}=\frac{\mathrm{K} \lambda}{(\beta \cos \theta)}
$$

Where $\lambda$ is the X-ray wavelength and equal to $1.54 \mathrm{~nm}, \beta$ is the full width of maximum height of a diffraction peak, $\theta$ is the diffraction angle, and $\mathrm{K}$ is the Scherrer's constant of the order of unity for the crystal. 


\section{1) Transmission electron microscopy (TEM)}

The particles size of silver colloidal nanoparticles solutions was examined by TEM. Few images of TEM, are displayed as in figure 7. The distribution of silver particles with crystalline in nature is observed at its higher concentration of solution; i.e $\mathrm{C}_{0}$. The morphology and sizes of silver nanoparticle at different resolution are also shown. The majority of nanoparticles are spherical in shape and about 2-40 $\mathrm{nm}$ in average diameter. Here, the first concentration was $2.5 \times 10-3 \mathrm{M}$, the second was $1.25 \times 10-3 \mathrm{M}$, the third was $1.56 \times 10-4 \mathrm{M}$ and the fourth was $7.8 \times 10-5 \mathrm{M}$. These have been illustrated in figure 7 respectively.
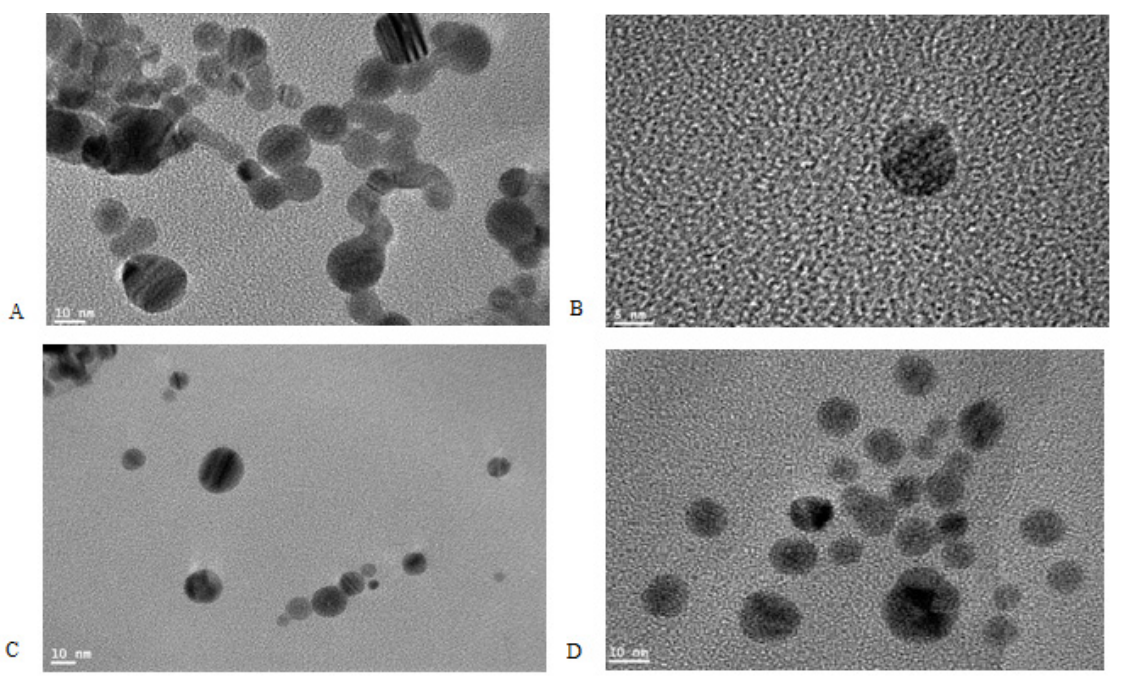

Figure 7. Typical TEM image of silver nanoparticles in water at different concentrations

\section{2) Photoacoustic (PA) Analysis}

The photoacoustic properties of silver nanoparticles were investigated under different conditions. The PA signal was monitored by changing parameters; such as, pump wavelengths, energy, repetition rate, concentrations and temperature. Figure 8 shows the outcomes for the photoacoustic signal of silver nanoparticles. The effects on PA signals by different parameters are systematically analyzed.

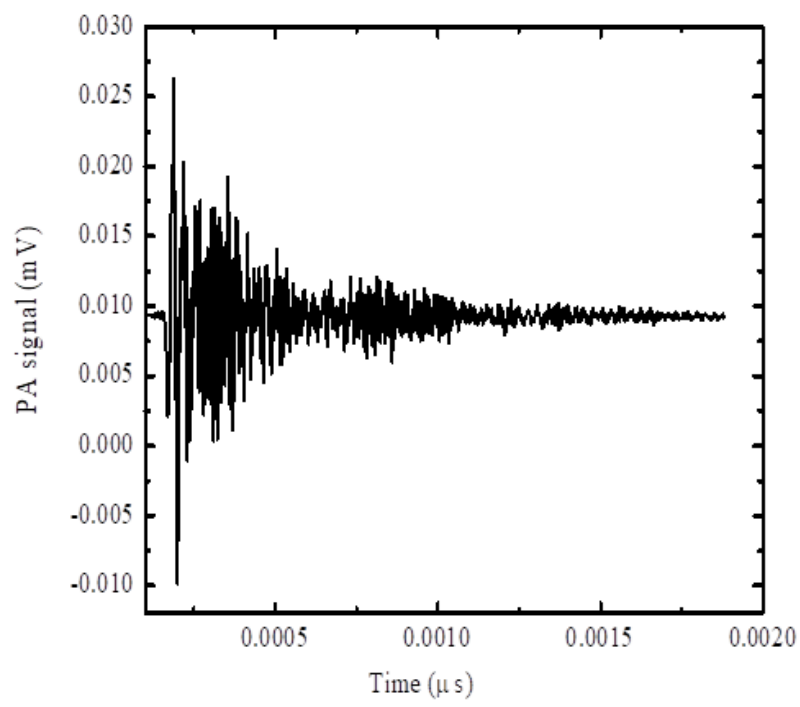

Figure 8. PA signal of silver nanoparticles $(\mathrm{C} 2)$ by Oscilloscope at $\mathrm{R}(\mathrm{r})=2 \mathrm{~Hz}, \mathrm{E}=30 \mathrm{~mJ}$ 
3) Photoacoustic (PA) signal vs wavelengths, input energy, repetition rate

The PA signal of silver nanoparticles solution was collected using a tunable Ti-sapphire laser source. The variable tunable wavelengths from $380 \mathrm{~nm}$ to $420 \mathrm{~nm}$ with constant repetition rate $10 \mathrm{~Hz}$ at constant incident energy $1 \mathrm{~mJ}$ for concentrations from $C_{1}$ to $C_{5}$, was used. The PA signals of silver nanoparticle solutions is shown in figure 9(a). The PA signal increases with increasing the concentration of silver nanoparticles in the solution. The maximum PA signal peak occurs at around $395 \mathrm{~nm}$ for all samples except the $\mathrm{C}_{3}$.

The behavior of PA signal of all samples over the variation of input laser energy was investigated. The effects on the PA signal due to pump energy was studied. The pump energy with a wavelength of $355 \mathrm{~nm}$ at a constant repetition rate of $2 \mathrm{~Hz}$ at $5-\mathrm{mJ}$ and $30 \mathrm{~mJ}$ was used for concentrations from $\mathrm{C}_{1}$ to $\mathrm{C}_{5}$. The comparison PA signal under the different energy is shown in Fig. 9(b). The influence of repetition rate on PA signal is clearly observed and increased the signal as repetition rate increased. The response of PA signal with respect to repetition rate for the $\mathrm{t}_{1}$ is significantly higher than $\mathrm{C}_{2}, \mathrm{C}_{3}, \mathrm{C}_{4}, \mathrm{C}_{5}$ of silver nanoparticles. PA signal is dependent on the concentration of silver nanoparticles as the repetition rate of laser pulses was varied. The best PA signals pronounced with the solution $\mathrm{C}_{1}$ at a laser repetition rate of $2 \mathrm{~Hz}$. Thus, the PA signals is increased as the concentration of particles decreased as seen in Fig. 9(c).
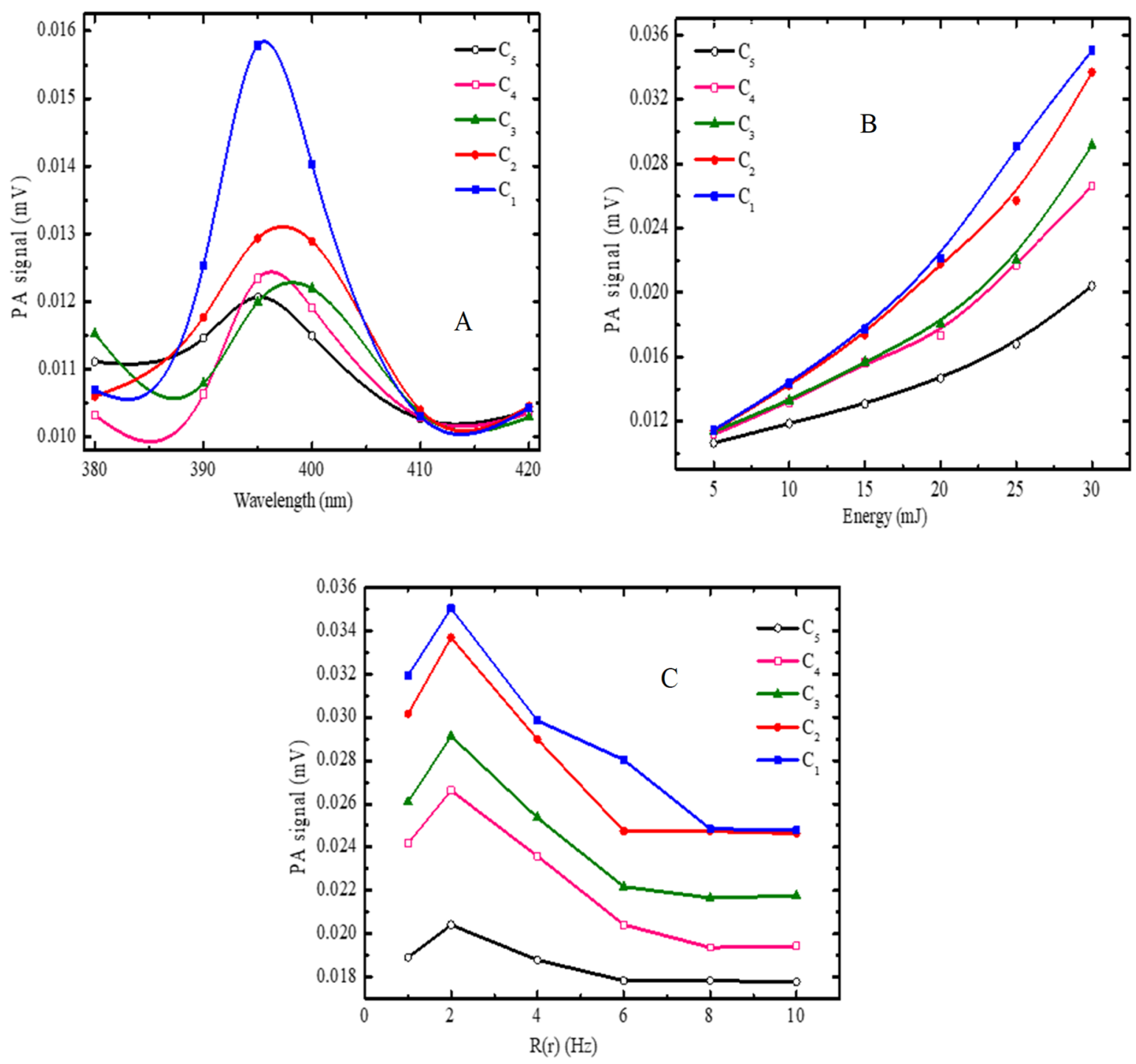

Figure 9. (a) PA signal vs. wavelength at $\mathrm{E}=1 \mathrm{~mJ}, \mathrm{R}(\mathrm{r})=10 \mathrm{~Hz}(\mathrm{~b}) \mathrm{PA}$ signal vs. Energy at $\mathrm{R}(\mathrm{r})=2 \mathrm{~Hz}(\mathrm{c}) \mathrm{PA}$ signal vs. $R(r)$ at $E=30 \mathrm{~mJ}$ 
4) Photoacoustic signal vs concentration and temperature

The behavior of PA signal for the different concentration of silver nanoparticles was also investigated. The 355 $\mathrm{nm}$ wavelength laser source with energy $30 \mathrm{~mJ}$ was used to measure the PA signal at different repetition rates (1, 2, 4, 6, 8, and $10 \mathrm{~Hz}$ ). The comparison of concentration vs. PA signals is shown in Figure 10(a). As the concentration increases, the PA signal surges and then becomes saturated. The highest PA signal is occurred with the concentration $\mathrm{C}_{1}$ at the repetition rate of $2 \mathrm{~Hz}$. In addition, when the repetition rate was changed at 5, 10, 15, 20, 25, and $30 \mathrm{~mJ}$; the behavior of PA signals for the same concentration was observed closely constant till at 15 $\mathrm{mJ}$ then increases the signal with respect to repetition rate. PA signals of all concentration are almost constant at 5,10 and 20 repetition rates, but significantly changed when repetition rate at 20,25 and $30 \mathrm{~mJ}$. The PA signal is observed higher for concentration $\mathrm{C}_{1}$ at the energy $30 \mathrm{~mJ}$ as seen in Fig. 10(b).

The effect of temperature on the PA signals of the solutions with different concentrations was investigated. When the temperature varies from $30{ }^{\circ} \mathrm{C}$ to $80{ }^{\circ} \mathrm{C}$ for the solutions $\mathrm{C}_{1}, \mathrm{C}_{2}, \mathrm{C}_{3}, \mathrm{C}_{4}$ and $\mathrm{C}_{5}$, significant decay in PA signal is observed. The effect of temperature on PA signal of silver nanoparticles under the $355 \mathrm{~nm}$ excitation wavelength at $2 \mathrm{~Hz}$ repetition rate and $20 \mathrm{~mJ}$ energy is shown as Figure 10. It may occur due to the effects on PA signal because of increased temperature in the solution, which lead to mobility of particles in the solution. Also, it is evident that in the first, second, third, and fourth concentrations, the PA signal decreases rapidly, which indicates that the silver nanoparticles are less aggregated due to heat from rising temperature. Increasing temperature on the solutions could rise heat the solution that may induce to separate particles. But in the fifth concentration, the silver nanoparticles seem to be aggregated due to sense less heat in the solution.
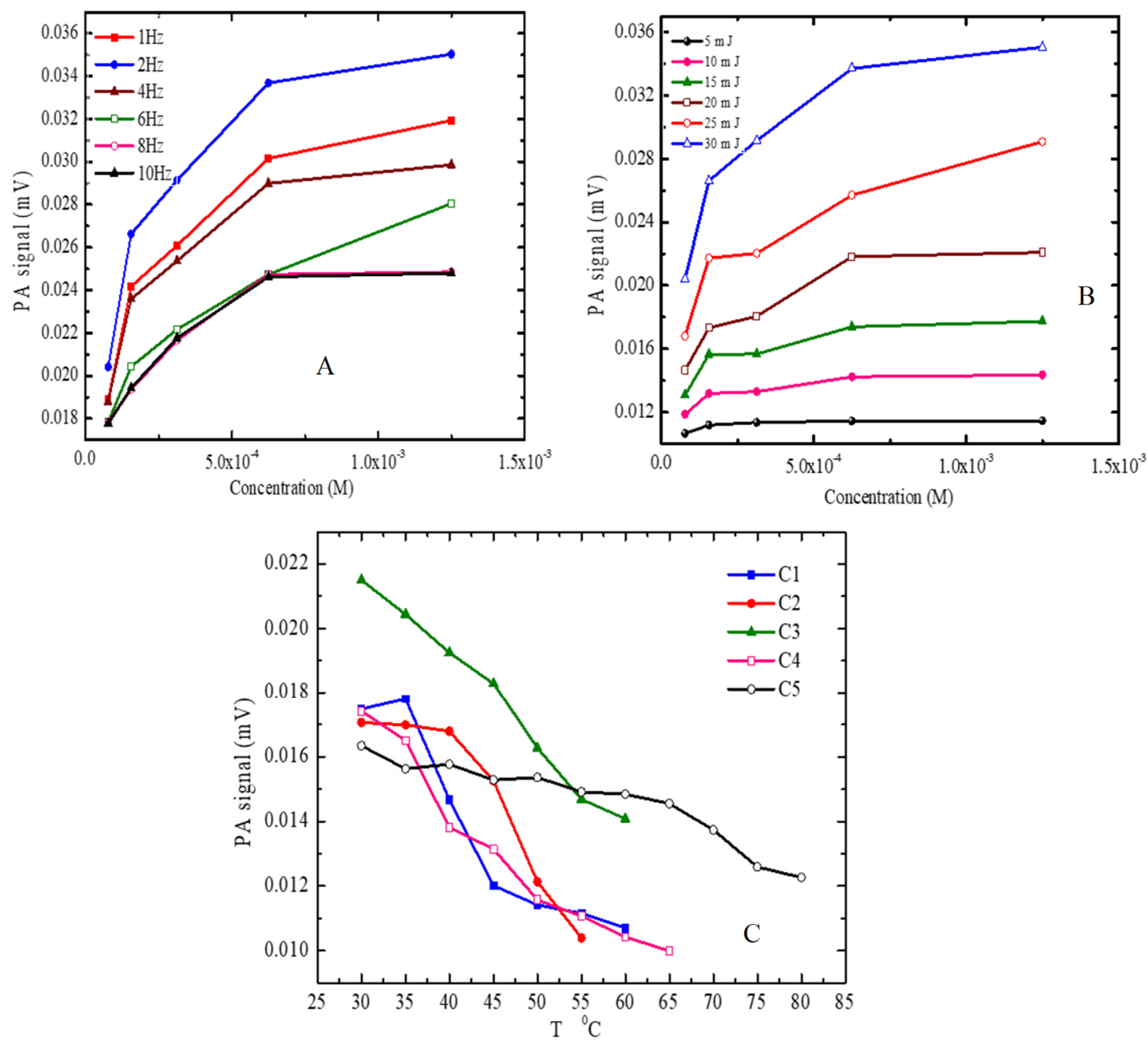

Figure 10. (a) PA signal vs. concentration of silver nanoparticles at $E=30 \mathrm{~mJ}$; (b) PA signal vs. concentration of silver nanoparticles at $\mathrm{R}(\mathrm{r})=2 \mathrm{~Hz}$; (c) PA signal v. Temp. of silver nanoparticles at $\mathrm{E}=20 \mathrm{~mJ}, \mathrm{R}(\mathrm{r})=2 \mathrm{~Hz}$ 
5) Photoacoustic signal vs fluorescence and absorption spectra

Fluorescence and absorption spectra of silver nanoparticles solution at different concentration were studied. The excitation wavelength was used at $355 \mathrm{~nm}$ to obtain the emission spectra for the solutions of $\mathrm{C}_{1}, \mathrm{C}_{2}, \mathrm{C}_{3}, \mathrm{C}_{4}$ and $\mathrm{C}_{5}$. Two emission peaks of silver nanoparticles are exhibited at $460 \mathrm{~nm}$ and $600 \mathrm{~nm}$. The emission intensity is decreased when concentration of particles in solutions increases as shown in figure 11.
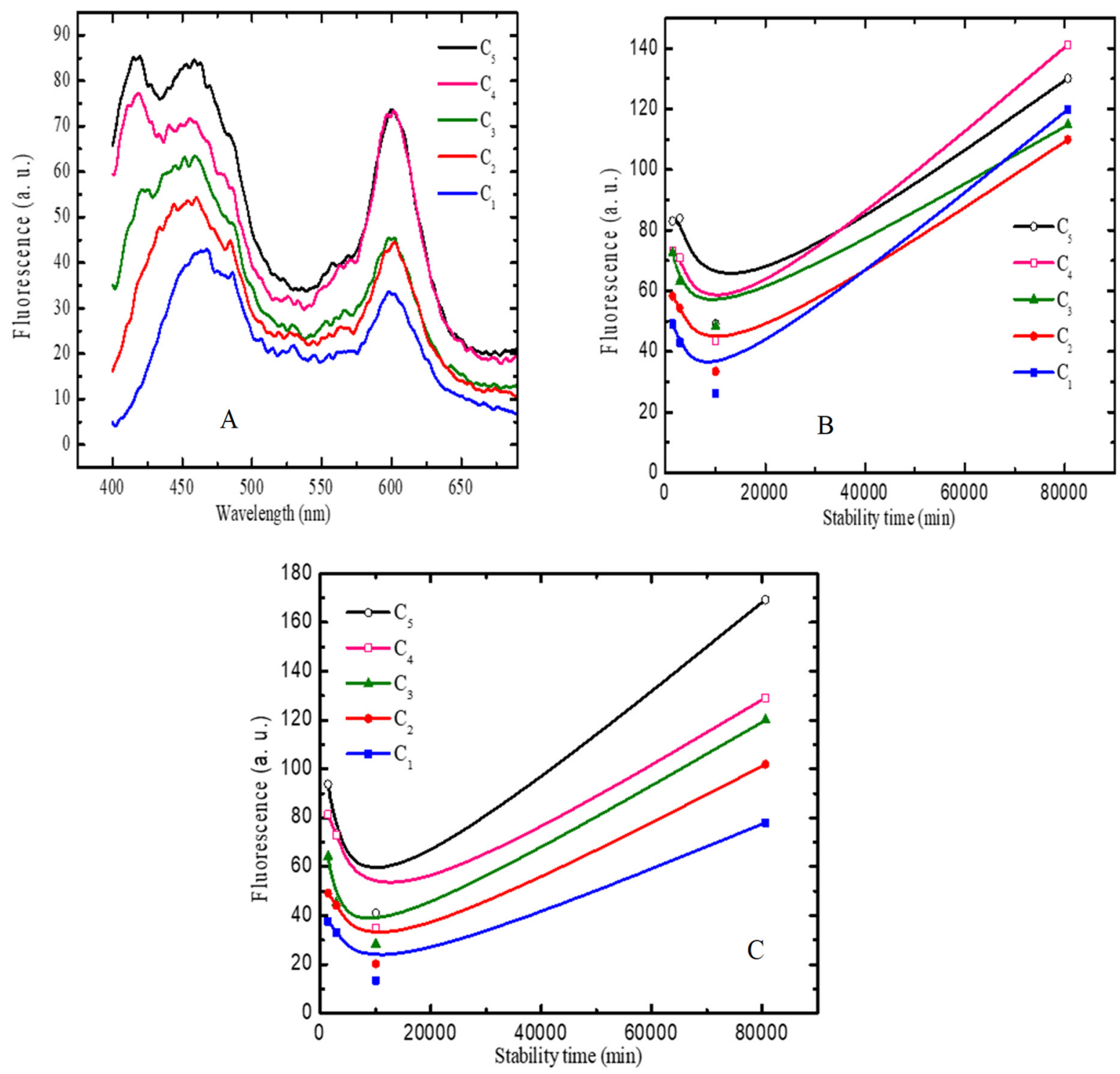

Figure 11. (a) Fluorescence of silver nanoparticles at different concentration; (b) Fluorescence vs. stability time of silver nanoparticles at peak 460nm; (c) Fluorescence vs. stability time of silver nanoparticles a peak $600 \mathrm{~nm}$

Stability of emission peaks for different solutions $\mathrm{C}_{1}, \mathrm{C}_{2}, \mathrm{C}_{3}, \mathrm{C}_{4}$ and $\mathrm{C}_{5}$ over the times was studied. The fluorescence vs. stability upon the times is also shown. The stability at peak $460 \mathrm{~nm}$ over time is observed as nonlinearity behavior with respect to the concentration. On the other hand, the fluorescence peak at $600 \mathrm{~nm}$ is observed to be dependent on concentration of nanoparticles in solution over the times i.e. stability curve is linearity with the percentage of concentration. In order to verify PA signals with respect to concentration of silver nanoparticles, PA signals were recorded on the basis of fluorescence with correspond to their concentration over the different period of time as shown in figure 12 . 

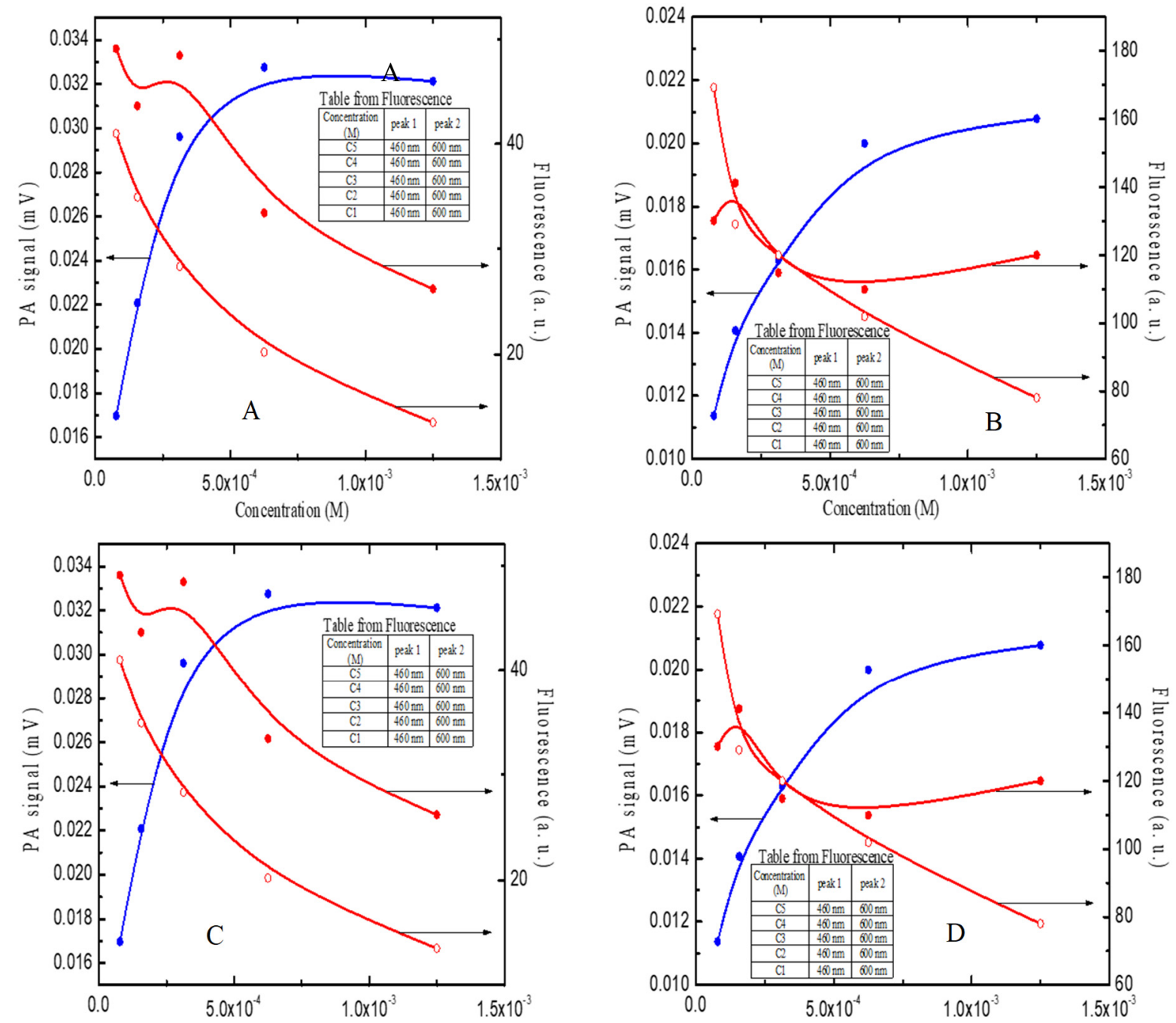

Figure 12. (a) PA signal and fluorescence vs. concentration of silver nanoparticles after 1 day; (b) PA signal and

fluorescence vs. concentration of silver nanoparticle after 2 days; (c) PA signal and Fluorescence vs.

concentration of silver nanoparticles after a week; (d) PA signal and Fluorescence vs. concentration of silver nanoparticles after 8 weeks

It is found that the PA signal of one day old solution is decreased, but upon the increasing concentration of silver nanoparticles, the PA signal is observed with the increment of fluorescence intensity as seen in figure 12. Fig. 12b shows the fluorescence intensity of 2 days old solution is trailed the same behavior but observed strong at the $\mathrm{C}_{5}$. Similarly, a week-old sample is observed as the increase in the fluorescence intensity upon the concentration increases and followed the improvement in PA signal. PA signal of one day old solution with decreasing concentration at both fluorescence peaks is increased in $\mathrm{C}_{3}$ then decline. The fluorescence peaks are observed to be increased with reducing the concentration of silver nanoparticles in solution. The PA signal and fluorescent peaks of the solution after two days to 8 weeks is also increased with decreasing the concentration, but there is slightly declined at fluorescent peak of 8 weeks old solution as shown in fig 12 (b, c, d). It means that evolution of PA signal may attribute to the lower densities of nanoparticles and also possibly be depend on the distribution of nanoparticles in the solution. The reason of different behavior on PA signal may possible due to the different interaction among silver nanoparticles and influence of laser pulse. In addition, the PA signal was found to be proportional to the laser pulse fluence on the sample surface as reported by Valverde-Alva et al. (2015).

Figure 13 shows the characteristic of PA signal vs. absorption peak of different concentration over the different time. The PA signal is increased with slightly increment on absorbance upon concentration and time. For instance, PA signals of one day old solution increases with increasing the concentration and absorption intensity but after $\mathrm{C}_{3}$, PA signal start to decrease. The PA signal of solution is observed with different behavior after the 2 days till 8 weeks, i.e. increases with slightly stable at absorbance as shown in figure $12(b, c, d)$. Therefore, the PA signal is 
observed higher after two days and also found to increase in the absorbance. Moreover, the response of PA signal is different when concentration increases, the PA signal increases, and the fluorescence decreases as seen in figure $13(\mathrm{a}, \mathrm{b}, \mathrm{c}, \mathrm{d})$.

As clearly seen in figure 13 (b, c d), that when concentration increases, the PA signal and absorbance are increased except the solution of one day old solution.

A
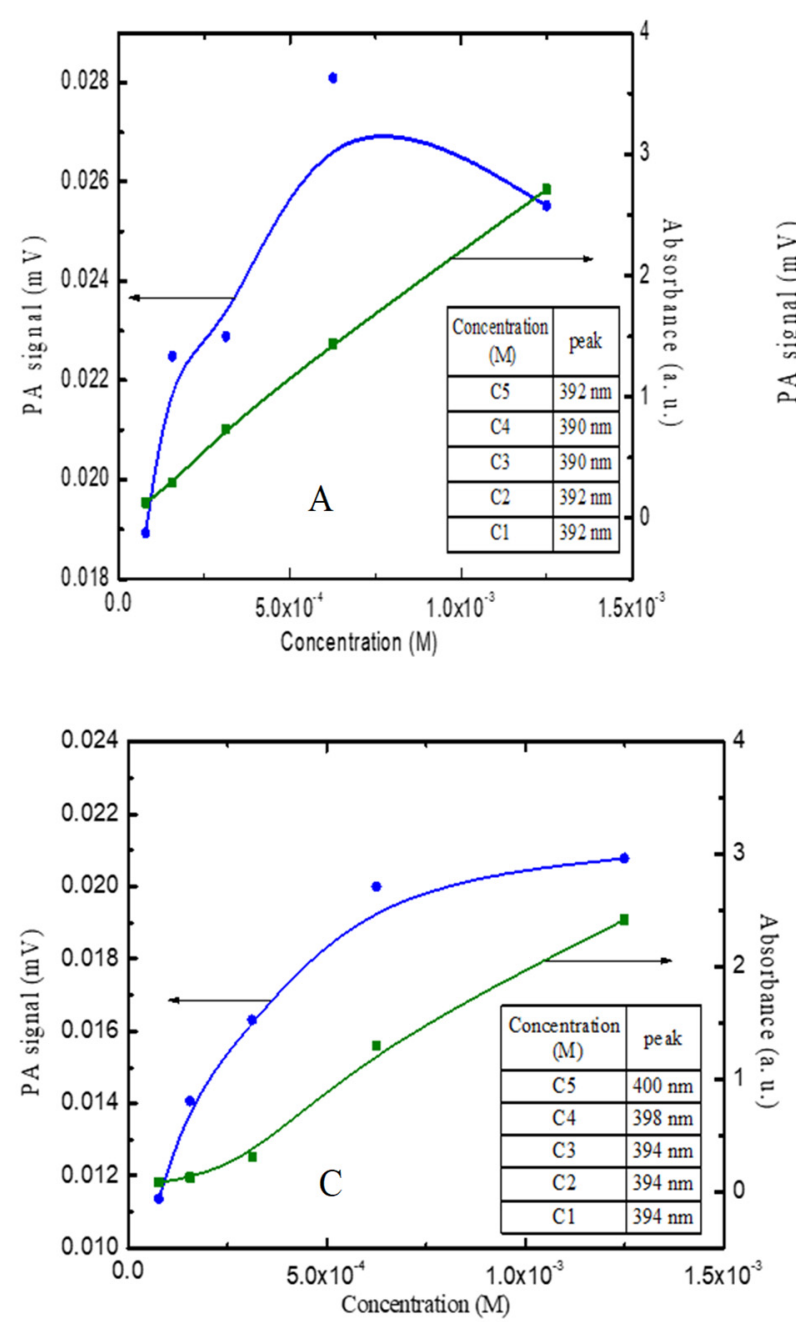
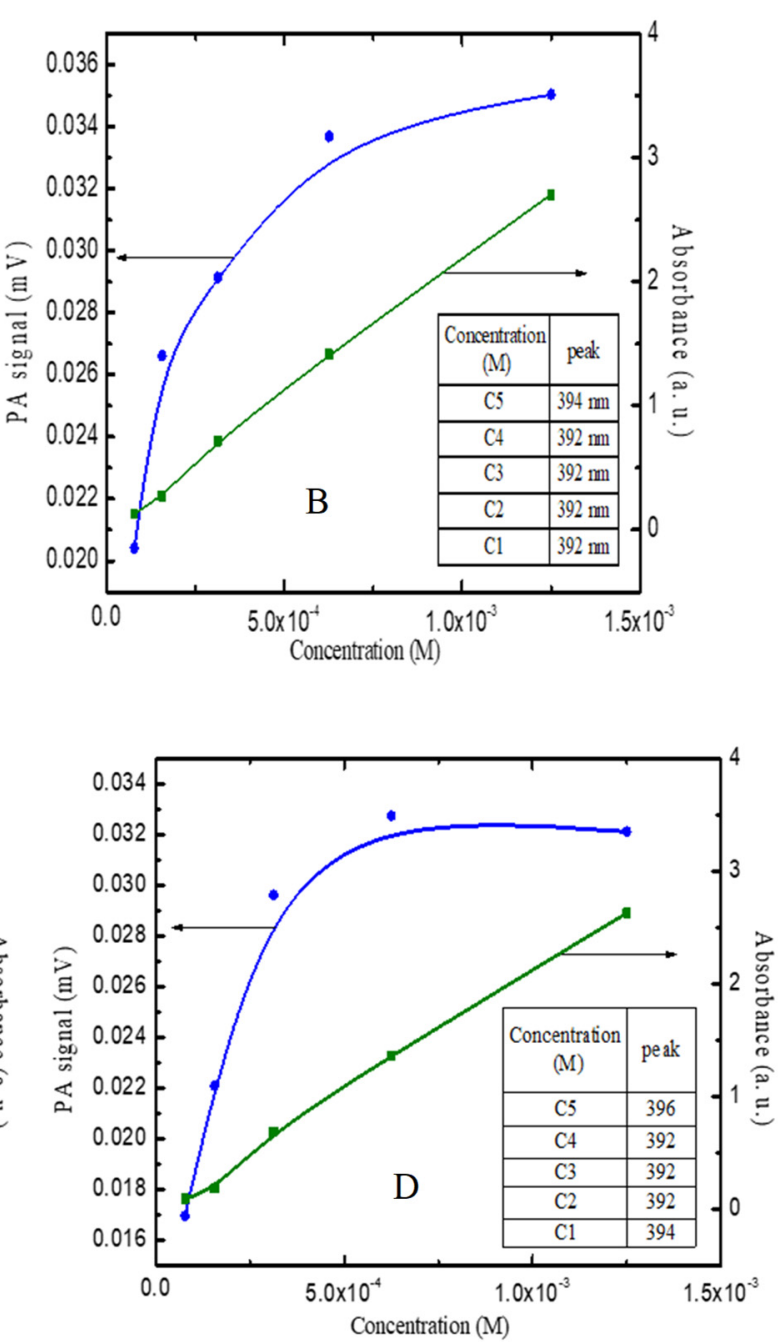

Figure 13. (a) PA signal and absorbance vs. concentration of silver nanoparticles after 1 day; (b) PA signal and absorbance vs. concentration of silver nanoparticles after 2 days; (c) PA signal and absorbance vs. concentration of silver nanoparticles after 8 weeks; (d) PA signal and absorbance vs. concentration of silver nanoparticles after a week

It may state that optical properties; such as, fluorescence, absorption and PA signal of silver nanoparticles are not stable over the times. The reason may attribute to chemical reaction in the solution that lead to influence on PA signal. Finally, figure 14 shows the evolution of PA signals of different solutions over the times. A systematic observation on PA signal with respect to different time for different concentration was conducted. The silver nanoparticles solution after the preparation of two days was seen to be remained the yellowish colour, which indicated that the particles are remained homogeneously in the solution. The PA signal is still found to be stronger up to 4-5 weeks, which means the particles are still suspended and stable in the solution. Therefore, the PA signal was decreased after 5 weeks and continuously decline till the lowest value for about $80640 \mathrm{~min}$ (about two months), 
indicating that some of silver nanoparticles are aggregated. It is assumed that the response of PA signal is still significant from the aggregated solutions. Such aggregation in the solutions was assumed due to the cellular uptake and endocytosis of nanoparticles (Bayer et al., 2013).

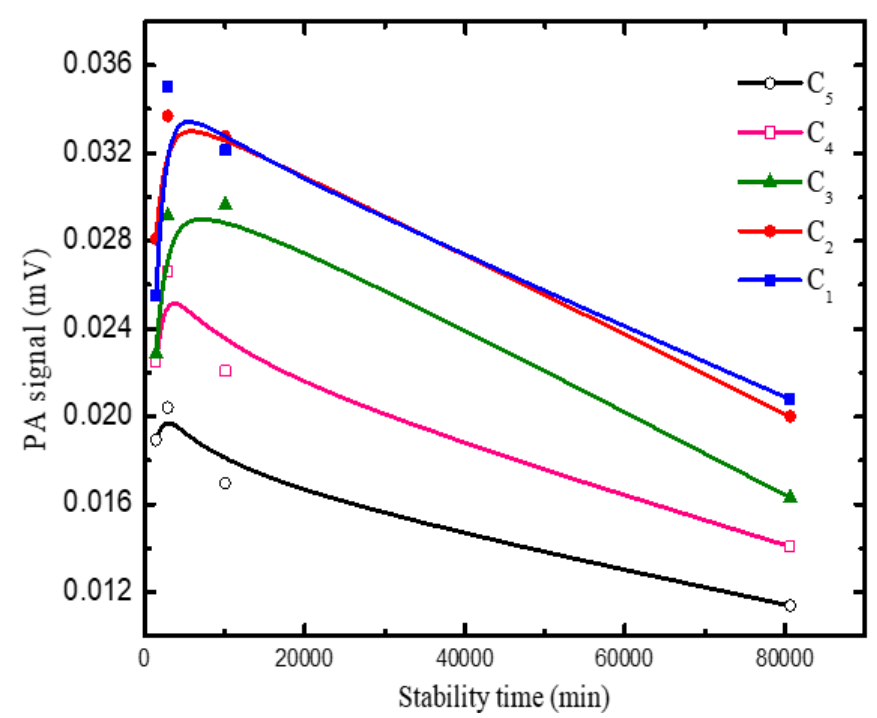

Figure 14. PA signal vs. stability time of silver nanoparticles

\section{Conclusion}

Colloidal silver nanoparticles in water solution at different concentration were successfully prepared. Optical and photoacaustic properties of colloidal solutions were studied. Absorption and fluorescence are greatly influenced by the concentration and duration of solution over time. Significant effect on photoacoustic signals is observed due to different parameters; such as, excitation wavelengths, input energy, repetition rate, concentration, temperature. Present results indicated that PA signals are dependent on the nature of distribution of silver nanoparticles, concentration, and duration of solution over time.

\section{Acknowledgment}

The author is very thankful to all the associated personnel in any reference that contributed in/for the purpose of this research.

\section{References}

Abbasi, E., Milani, M., Fekri Aval, S., Kouhi, M., Akbarzadeh, A., Tayefi Nasrabadi, H., ... \& Samiei, M. (2016). Silver nanoparticles: synthesis methods, bio-applications and properties. Critical reviews in microbiology, 42(2), 173-180.

Alivisatos, A. P. (1996). Semiconductor clusters, nanocrystals, and quantum dots. science, 271(5251), 933-937.

Amendola, V., \& Meneghetti, M. (2009). Laser ablation synthesis in solution and size manipulation of noble metal nanoparticles. Physical chemistry chemical physics, 11(20), 3805-3821.

Bayer, C. L., Nam, S. Y., Chen, Y. S., \& Emelianov, S. Y. (2013). Photoacoustic signal amplification through plasmonic nanoparticle aggregation. Journal of biomedical optics, 18(1), 016001.

Bell. A. G. (1881). Production of sound by radiant energy, J. Franklin Inst., 111(6), 401-426.

Bohren, C. F., \& Huffman, D. R. (1983). Absorption and scattering of light by small particles. New York: Wiley.

Borsella, E., Gonella, F., Mazzoldi, P., Quaranta, A., Battaglin, G., \& Polloni, R. (1998). Spectroscopic investigation of silver in soda-lime glass. Chemical Physics Letters, 284(5-6), 429-434.

Cao, G. (2004). Nanostructures \& nanomaterials: synthesis, properties \& applications. Imperial college press.

Chang, L. T., \& Yen, C. C. (1995). Studies on the preparation and properties of conductive polymers. VIII. Use of heat treatment to prepare metallized films from silver chelate of PVA and PAN. Journal of applied polymer science, 55(2), 371-374. 
Chen, D., Qiao, X., Qiu, X., \& Chen, J. (2009). Synthesis and electrical properties of uniform silver nanoparticles for electronic applications. Journal of materials science, 44(4), 1076-1081.

Emelianov, S. Y., Aglyamov, S. R., Shah, J., Sethuraman, S., Scott, W. G., Schmitt, R., ... \& Oraevsky, A. A. (2004). Combined ultrasound, optoacoustic, and elasticity imaging. In Photons Plus Ultrasound: Imaging and Sensing (Vol. 5320, pp. 101-113). International Society for Optics and Photonics.

Emelianov, S., Aglyamov, S., Shah, J., Sethuraman, S., Scott, G., Schmitt, R., ... \& Oraevsky, A. (2004). Synergy of ultrasound, elasticity, and optoacoustic imaging for improved detection and differentiation of cancerous tissue. The Journal of the Acoustical Society of America, 115(5), 2411-2411.

Ferrari, M., Montagna, M., Ronchin, S., Rossi, F., \& Righini, G. C. (1999). Waveguide luminescence and Raman spectroscopy: Characterization of an inhomogeneous film at different depths. Applied physics letters, 75(11), 1529-1531.

Förster, S., \& Antonietti, M. (1998). Amphiphilic block copolymers in structure-controlled nanomaterial hybrids. Advanced Materials, 10(3), 195-217.

Fukasawa, T., Shinto, H., Aoki, H., Ito, S., \& Ohshima, M. (2014). Size-dependent effect of gold nanospheres on the acoustic pressure pulses from laser-irradiated suspensions. Advanced Powder Technology, 25(2), 733738.

Garitaonandia, J. S., Insausti, M., Goikolea, E., Suzuki, M., Cashion, J. D., Kawamura, N., ... \& Rojo, T. (2008). Chemically induced permanent magnetism in $\mathrm{Au}, \mathrm{Ag}$, and $\mathrm{Cu}$ nanoparticles: localization of the magnetism by element selective techniques. Nano Letters, 8(2), 661-667.

Hao, E., \& Schatz, G. C. (2004). Electromagnetic fields around silver nanoparticles and dimers. The Journal of chemical physics, 120(1), 357-366.

Hatef, A., Darvish, B., Dagallier, A., Davletshin, Y. R., Johnston, W., Kumaradas, J. C., ... \& Meunier, M. (2015). Analysis of photoacoustic response from gold-silver alloy nanoparticles irradiated by short pulsed laser in water. The Journal of Physical Chemistry C, 119(42), 24075-24080.

Jin, R., Cao, Y., Mirkin, C. A., Kelly, K. L., Schatz, G. C., \& Zheng, J. G. (2001). Photoinduced conversion of silver nanospheres to nanoprisms. science, 294(5548), 1901-1903.

Kreibig, U., \& Vollmer, M. (2013). Optical properties of metal clusters (Vol. 25). Springer Science \& Business Media.

Kruger, R. A. (1994). Photoacoustic ultrasound. Medical physics, 21(1), 127-131.

Ku, G., Wang, X., Xie, X., Stoica, G., \& Wang, L. V. (2005). Imaging of tumor angiogenesis in rat brains in vivo by photoacoustic tomography. Applied optics, 44(5), 770-775.

Link, S., \& El-Sayed, M. A. (1999). Spectral properties and relaxation dynamics of surface plasmon electronic oscillations in gold and silver nanodots and nanorods.

Liz-Marzán, L. M. (2006). Tailoring surface plasmons through the morphology and assembly of metal nanoparticles. Langmuir, 22(1), 32-41.

May, A. (2008). Characterization of CdS and $\mathrm{ZnS}$ quantum dots prepared via a chemical method on SBR latex.

Mock, J. J., Barbic, M., Smith, D. R., Schultz, D. A., \& Schultz, S. (2002). Shape effects in plasmon resonance of individual colloidal silver nanoparticles. The Journal of Chemical Physics, 116(15), 6755-6759.

Oraevsky, A. A., Jacques, S. L., \& Tittel, F. K. (1997). Measurement of tissue optical properties by time-resolved detection of laser-induced transient stress. Applied optics, 36(1), 402-415.

Oseguera-Galindo, D. O., Martinez-Benitez, A., Chavez-Chavez, A., Gomez-Rosas, G., Perez-Centeno, A., \& Santana-Aranda, M. A. (2012). Effects of the confining solvent on the size distribution of silver NPs by laser ablation. Journal of Nanoparticle Research, 14(9), 1133.

Ozin, G. A. (1992). Nanochemistry: synthesis in diminishing dimensions. Advanced Materials, 4(10), 612-649.

Pal, S., Tak, Y. K., \& Song, J. M. (2007). Does the antibacterial activity of silver nanoparticles depend on the shape of the nanoparticle? A study of the gram-negative bacterium Escherichia coli. Applied and environmental microbiology, 73(6), 1712-1720.

Popok, V. N., Stepanov, A. L., \& Odzhaev, V. B. (2005). Synthesis of silver nanoparticles by the ion implantation method and investigation of their optical properties. Journal of Applied Spectroscopy, 72(2), 229-234. 
Pyatenko, A., Yamaguchi, M., \& Suzuki, M. (2007). Synthesis of spherical silver nanoparticles with controllable sizes in aqueous solutions. The Journal of Physical Chemistry C, 111(22), 7910-7917.

Schröfel, A., Kratošová, G., Šafařík, I., Šafaříková, M., Raška, I., \& Shor, L. M. (2014). Applications of biosynthesized metallic nanoparticles-A review. Acta biomaterialia, 10(10), 4023-4042.

Shiraishi, Y., \& Toshima, N. (2000). Oxidation of ethylene catalyzed by colloidal dispersions of poly (sodium acrylate)-protected silver nanoclusters. Colloids and Surfaces A: Physicochemical and Engineering Aspects, 169(1-3), 59-66.

Sun, T., \& Seff, K. (1994). Silver clusters and chemistry in zeolites. Chemical reviews, 94(4), 857-870.

Sun, Y., \& Xia, Y. (2002). Shape-controlled synthesis of gold and silver nanoparticles. Science, 298(5601), 21762179.

Valverde-Alva, M. A., García-Fernández, T., Villagrán-Muniz, M., Sánchez-Aké, C., Castañeda-Guzmán, R., Esparza-Alegría, E., ... \& Herrera, C. M. (2015). Synthesis of silver nanoparticles by laser ablation in ethanol: a pulsed photoacoustic study. Applied Surface Science, 355, 341-349.

Villegas, M. A., Fernández Navarro, J. M., Paje, S. E., \& Llopis, J. (1996). Optical spectroscopy of a soda lime glass exchanged with silver. Physics and chemistry of glasses, 37(6), 248-253.

Wang, P. W., Zhang, L., Tao, Y., \& Wang, C. (1997). Thermal Behavior of Silver in Ion-Exchanged Soda-Lime Glasses. Journal of the American Ceramic Society, 80(9), 2285-2293.

Wang, X., \& Chen, Y. (2008). A new two-phase system for the preparation of nearly monodisperse silver nanoparticles. Materials Letters, 62(28), 4366-4368.

Wang, X., Xu, Y., Xu, M., Yokoo, S., Fry, E. S., \& Wang, L. V. (2002). Photoacoustic tomography of biological tissues with high cross-section resolution: Reconstruction and experiment. Medical physics, 29(12), 27992805.

\section{Copyrights}

Copyright for this article is retained by the author(s), with first publication rights granted to the journal.

This is an open-access article distributed under the terms and conditions of the Creative Commons Attribution license (http://creativecommons.org/licenses/by/4.0/). 